\title{
NEW ELECTRONIC DIDACTIC TOOL FOR NONLINEAR SYSTEMS LABORATORY
}

\author{
Karel Perutka \\ Faculty of Applied Informatics, Tomas Bata University in Zlin \\ kperutka@fai.utb.cz
}
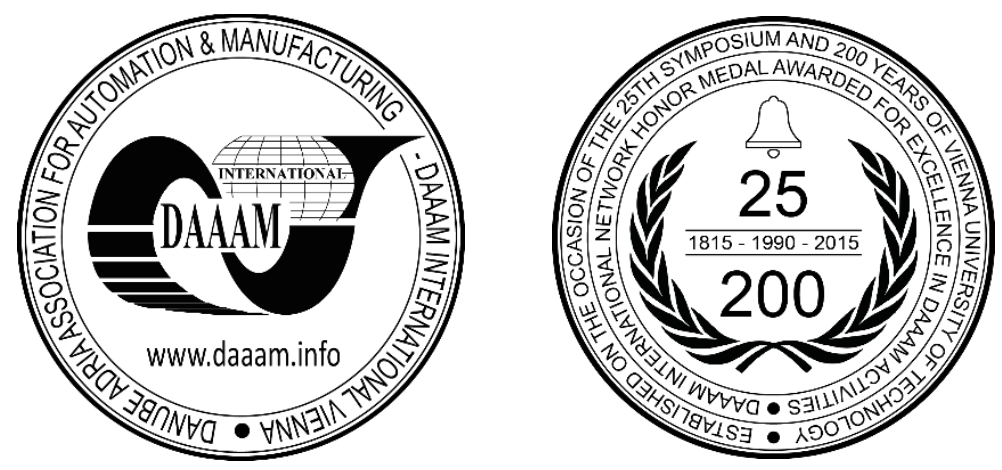

This Publication has to be referred as: Perutka, K[arel] (2016). New Electronic Didactic Tool for Nonlinear Systems Laboratory, Proceedings of the 27th DAAAM International Symposium, pp.0023-0033, B. Katalinic (Ed.), Published by DAAAM International, ISBN 978-3-902734-08-2, ISSN 1726-9679, Vienna, Austria

DOI: $10.2507 / 27$ th.daaam.proceedings.004

\begin{abstract}
The paper presents new electronic didactic tool that was created for the laboratory where nonlinear systems are taught and practiced by simulations. The tool in the laboratory works with several control strategies and models of nonlinear systems including Hammerstein and Wiener models and it was created in MATLAB and SIMULINK environment. Students had worked with it during last semester and positively evaluated it which is summarized at the end of the paper.
\end{abstract}

Keywords: Didactic tool; Hammerstein model; MATLAB; Nonlinear control; SIMULINK; Wiener model.

\section{Introduction}

Most of the physical, biological, chemical, economical systems are nonlinear in the real world. In the engineering practice, the nonlinear systems are almost everywhere. There is often possible to control most of the nonlinear systems using the methods for linear control, but only in the close area of steady states. Nonlinear control enlarges the area of control of such systems. Some systems have nonlinearities which are hardly linearly approximated and therefore, there is necessary or useful to employ the nonlinear control [28]. Nonlinear control is of big interest during last years which is proved by the huge amount of publications.

There is always necessary to have the theoretical background for practical applications. Methods of nonlinear control are developing very fast and in huge amount of them can be found in the literature, such as stability analysis of nonlinear systems [3], optimal nonlinear control of continuous systems by adaptive dynamic programming [7], optimal control of nonlinear time delay systems [8], robust decentralized control methodology for a class of interconnected nonlinear systems [9], fuzzy dynamic surface control for uncertain nonlinear systems under input saturation [10], adaptive control for a class of switched nonlinear systems with modelled dynamics [11], targets tracking algorithm for a class of nonlinear systems with feedforward compensations [12], block oriented feedforward control [13], fuzzy control for uncertain nonaffine nonlinear systems with dead-zone inputs [15], over-coming time-domain performance limitation by nonlinear control [17], and, finally, the adaptive self-structuring fuzzy control for nonlinear uncertain systems [32].

Modelling of many nonlinear systems is based on Hammerstein and Wiener models, as can be also proven by many publications during last years. Some publications are just focused on Hammerstein models and the other ones for Wiener 
models. But there are also papers dealing with of these models, for example the paper describing the recovering the Wiener-Hammerstein nonlinear state-space models using linear algebra [21], or control, such as the robust model predictive control of nonlinear processes represented by Wiener or Hammerstein models [29], and nonlinear predictive control for Hammerstein-Wiener systems [27].

Hammerstein models are mentioned for example in applications to $\mathrm{pH}$ process control, where is used the poleplacement self-tuning control of nonlinear Hammerstein system [30], or in servo systems, where is employed the nonlinear modelling and predictive functional control of Hammerstein system [31], or like a recursive parametric estimation algorithm of multivariable systems described by Hammerstein models [26].

Wiener models are also used, for example as a robust nonlinear internal model control of stable Wiener systems [20], or block-oriented feedforward control with demonstration to Wiener modelling [25], or modelling of memristor-based chaotic systems using nonlinear Wiener adaptive filters [24]. Identification of such systems is solve for example by the recursive least squares algorithm [22].

Nonlinear systems and their control can be found in many areas, for example using nonlinear model predictive control in automotive industry [6], receding horizon control of vehicle formation [16], stochastic nonlinear model predictive control in film deposition [2], nonlinear PI control of wind turbine [14], neural network for model predictive control of continuous reactor [23], nonlinear model predictive control of robot manipulator [18], steam valve control of multimachine power systems [1], or controlling galloping vibrations [4], nonlinear control of boost converter [19], adaptive control of nonlinear finance system [5], to name some. During last years, nice implementation of new creative educational technologies for inter-university network was realized [33].

Most of the papers mentioned hereinbefore are so nice that they will definitely be used in future to enlarge tasks portfolio in the laboratory of automation where several systems and methods are verified by simulations in MATLAB.

After introductory part, the created models are presented. These models were used in the new electronic didactic tool, which described after that. Finally, there was done the evaluation of the created didactic tool in the form of the questionnaire. The results are presented in the graphs. There were no more studies about this topic at my university and therefore the theme and its realisation is the unique one.

\section{Created Models}

For the laboratory, there were created and used following models with nonlinearities which are based on the previous work of my student [28].

\subsection{Spherical Fluid Reservoir}

The balance equation is used to create the mathematical model of the reservoir

$$
\begin{aligned}
& \text { input }=\text { output }+ \text { accumulation } \\
& q_{v}=q+\frac{d V}{c t} \\
& q=a \sqrt{h}
\end{aligned}
$$

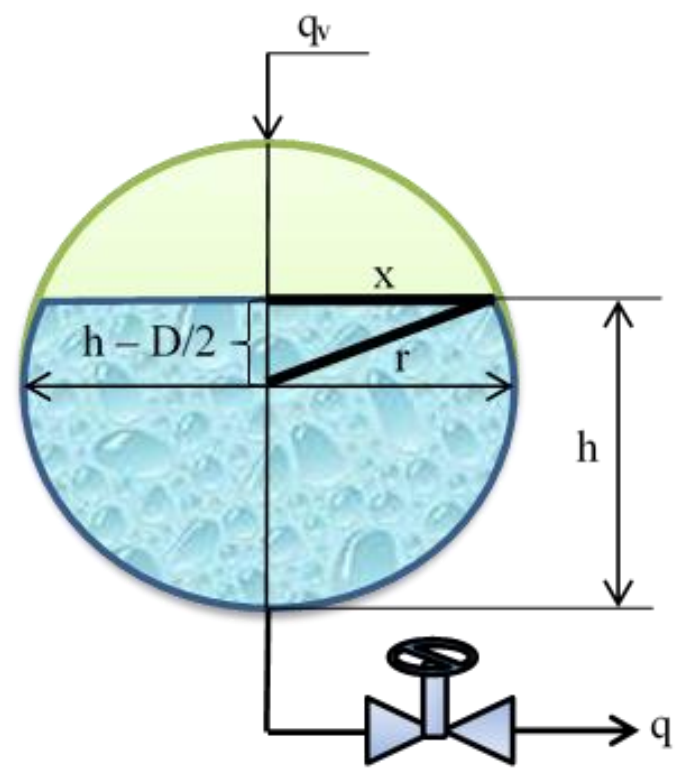

Fig. 1. Scheme of the spherical fluid reservoir 
and for the accumulation it holds

$$
\begin{aligned}
& \frac{d V}{d t}=S \frac{d h}{d t} \\
& S=S(h)=\pi x^{2} \\
& x^{2}=\left(\frac{D}{2}\right)^{2}-\left(h-\frac{D}{2}\right)^{2}=h D-h^{2}=h(D-h)
\end{aligned}
$$

Then we can easily derive that

$$
\begin{aligned}
& q_{v}-q=S \frac{d h}{d t} \\
& \frac{d h}{d t}=\frac{1}{\pi h(D-h)}\left(q_{v}-a \sqrt{h}\right), h(0)=h^{S}
\end{aligned}
$$

where $q_{v}\left(\mathrm{~m}^{3} . \mathrm{s}^{-1}\right)$ is the volumetric in-flow of the liquid, $S\left(\mathrm{~m}^{2}\right)$ is the cross-section of the reservoir, $D(\mathrm{~m})$ is the reservoir diameter, $h(\mathrm{~m})$ is the liquid height in the reservoir, $a\left(\mathrm{~m} \cdot \mathrm{s}^{-1}\right)$ is the known constant of the valve.

It is clear from the equations that it is single input single output system with nonlinearities - division and root. Now we select the state space variables as $x=h$ and $u=q_{v}$ and we obtain the nonlinear system

$$
\begin{aligned}
\dot{x} & =\frac{1}{\pi x(D-x)}(u-a \sqrt{x}) \\
f & =\frac{-a \sqrt{x}}{\pi x(D-x)} \\
G & =\frac{1}{\pi x(D-x)}
\end{aligned}
$$

In case that volumetric flow of liquid $q_{v}$ is random, we suppose it as unmeasurable disturbance $v$, i.e. $q_{v}=v$. Mathematical model of the reservoir is than

$$
\begin{aligned}
\dot{x} & =\frac{1}{\pi x(D-x)}(u-v) \\
f & =\frac{-v}{\pi x(D-x)} \\
G & =\frac{1}{\pi x(D-x)}
\end{aligned}
$$

Next two pictures display the scheme of these 2 models in MATLAB-SIMULINK software.

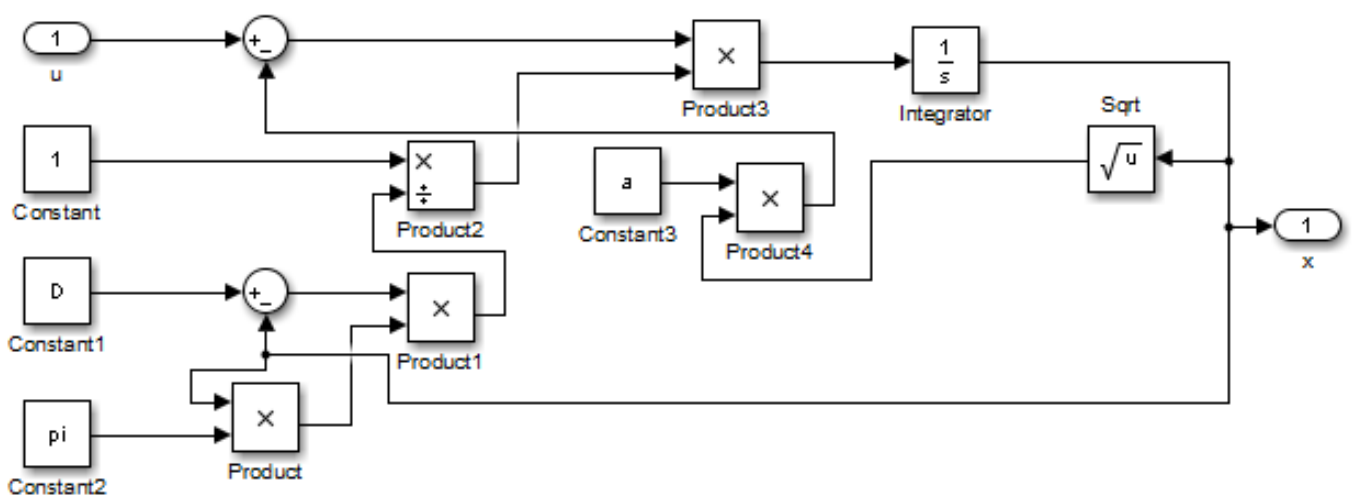

Fig. 2. Model of the spherical fluid reservoir in MATLAB-SIMULINK environment 


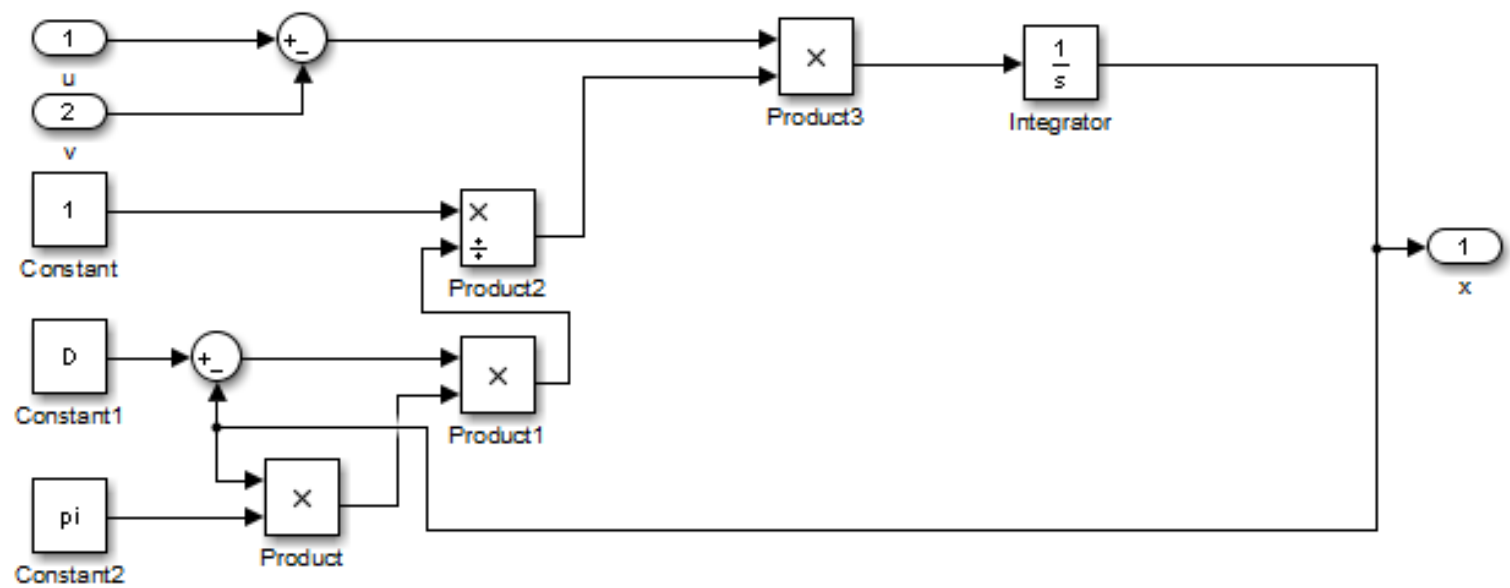

Fig. 3. Model of the spherical fluid reservoir with disturbance in MATLAB-SIMULINK environment

\subsection{Inverse Conical Fluid Reservoir with Non-Constant Cross Section}

We use equation 1 as the balance equation to get the mathematical model of the reservoir and for the accumulation in the reservoir it holds

$\frac{d V}{d t}=S \frac{d h}{d t}$

$S=S(h)$

$\operatorname{tg} \alpha=\frac{x}{h}=\frac{d / 2}{H}$

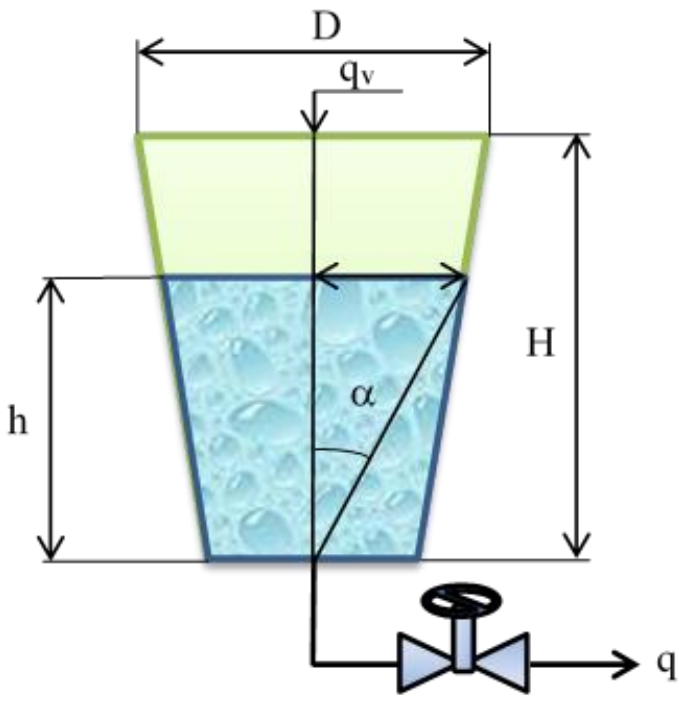

Fig. 4. Scheme of the inverse conical fluid reservoir with non-constant cross section

$S=S(h)=\pi x^{2}$

$\frac{d V}{d t}=\pi \frac{D}{4 H^{2}} h^{2} \frac{d h}{d t}$

Than we can derive that

$$
\begin{aligned}
& q_{v}-q=S \frac{d h}{d t} \\
& \frac{d h}{d t}=\frac{4 H^{2}}{\pi D^{2} h^{2}}\left(q_{v}-a \sqrt{h}\right), h(0)=h^{S}
\end{aligned}
$$


where $q_{v}\left(\mathrm{~m}^{3} . \mathrm{s}^{-1}\right)$ is the volumetric in-flow of the liquid, $S\left(\mathrm{~m}^{2}\right)$ is the cross-section of the reservoir, $D(\mathrm{~m})$ is the reservoir diameter, $h(\mathrm{~m})$ is the liquid height in the reservoir, $H(\mathrm{~m})$ is the reservoir height, $a\left(\mathrm{~m} \cdot \mathrm{s}^{-1}\right)$ is the known constant of the valve.

It is clear from the equations that it is again the single input single output system with nonlinearities - division and root. Now we select the state space variables as $x=h$ and $u=q_{v}$ and we obtain the nonlinear system

$$
\begin{aligned}
& \dot{x}=\frac{4 H^{2}}{\pi D^{2} h^{2}}(u-a \sqrt{x}) \\
& f(x)=-\frac{4 H^{2}}{\pi D^{2} h^{2}} a \sqrt{x} \\
& G(x)=\frac{4 H^{2}}{\pi D^{2} h^{2}}
\end{aligned}
$$

In case that the volumetric flow of the liquid $q_{v}$ is random, we suppose it as unmeasurable disturbance $v$, i.e. $q_{v}=v$. Mathematical model of the reservoir is than

$$
\begin{aligned}
& \dot{x}=\frac{4 H^{2}}{\pi D^{2} h^{2}}(u-v) \\
& f(x)=-\frac{4 H^{2}}{\pi D^{2} h^{2}} v \\
& G(x)=\frac{4 H^{2}}{\pi D^{2} h^{2}}
\end{aligned}
$$

Next two pictures display the scheme of these 2 models in MATLAB-SIMULINK software.

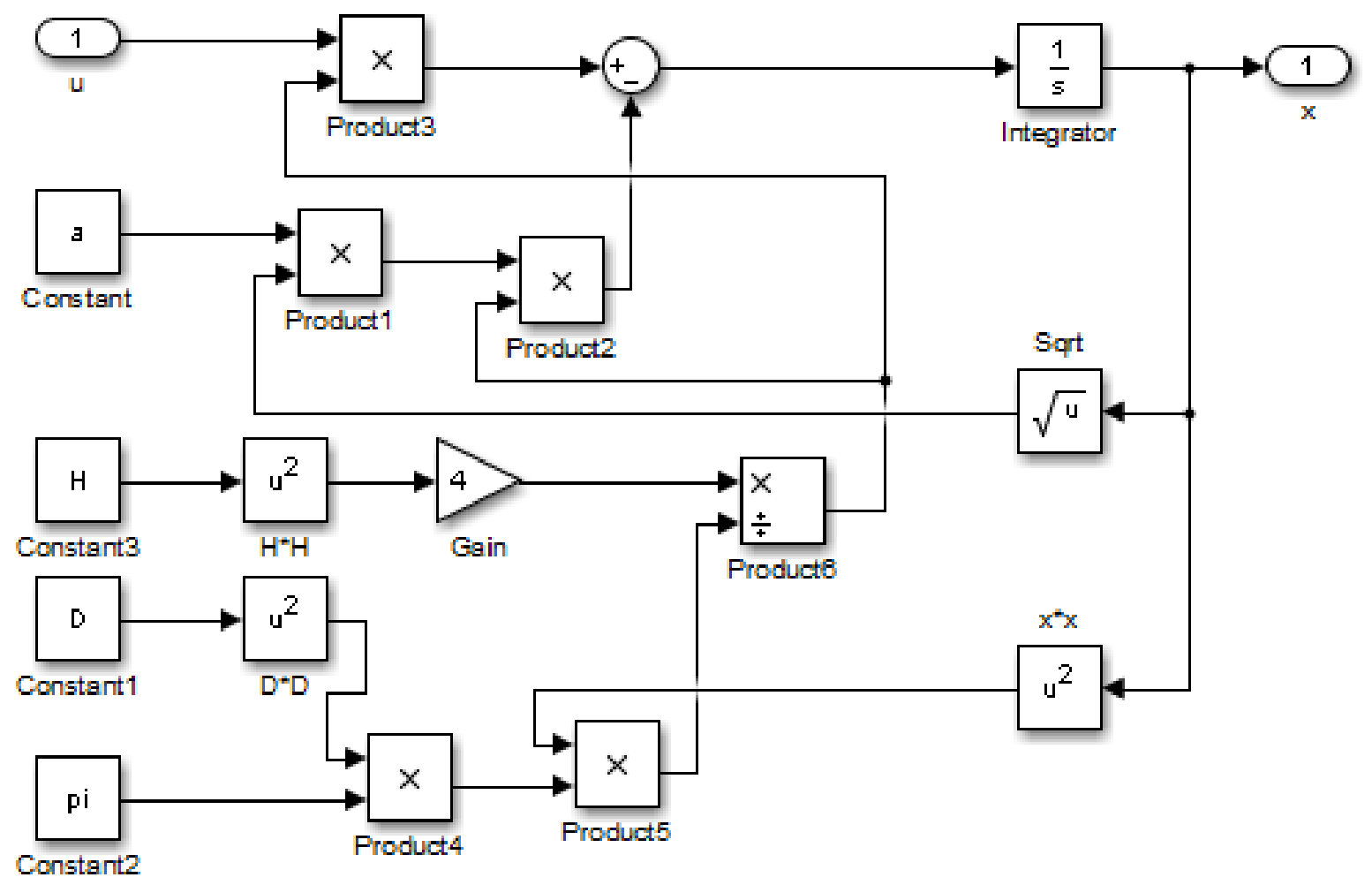

Fig. 5. Model of the inverse conical fluid reservoir with non-constant cross section in MATLAB-SIMULINK environment 


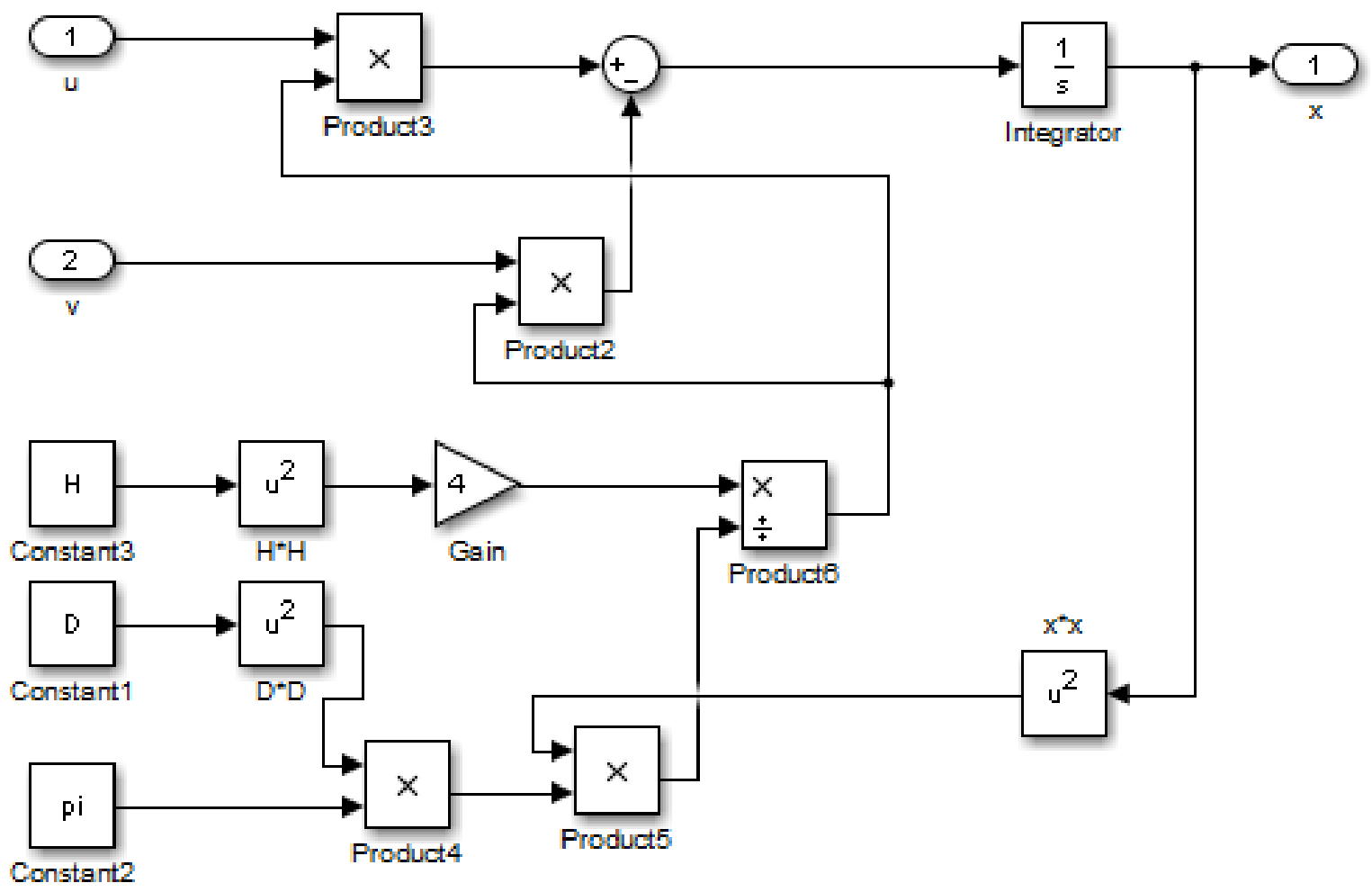

Fig. 6. Model of the inverse conical fluid reservoir with non-constant cross section with disturbance in MATLABSIMULINK environment

\subsection{Cylindrical Flow Heat Exchanger with Stirring}

We can also use the balance equation to get the mathematical model as

$$
\begin{aligned}
& \frac{d T}{d t}=-\frac{S \alpha}{V \rho c_{p}} T+\frac{S \alpha}{V \rho c_{p}} T_{c}+\frac{T_{v}-T}{V} q \\
& \frac{d T_{c}}{d t}=-\frac{S \alpha}{V_{c} \rho_{c} c_{p c}} T+\frac{S \alpha}{V_{c} \rho_{c} c_{p c}} T_{c}+\frac{T_{c v}-T_{c}}{V_{c}} q_{c}
\end{aligned}
$$

$q \geq 0, q_{c} \geq 0$

where $q$ and $q_{c}\left(\mathrm{~m}^{3} \cdot \mathrm{s}^{-1}\right)$ are the volumetric flows of the liquid, $S\left(\mathrm{~m}^{2}\right)$ is the heat transfer surface of the heat exchanger, $T_{v}$ and $T_{c v}\left({ }^{\circ} \mathrm{C}\right)$ are the input temperatures of the liquid in-flows in the heat exchanger, $T$ and $T_{c}\left({ }^{\circ} \mathrm{C}\right)$ are the temperatures of the warmer and cooler liquid in the heat exchanger, $c_{p}$ and $c_{p c}\left(\mathrm{~kJ} \mathrm{~kg}^{-1} \cdot \mathrm{K}^{-1}\right)$ are the specific heat capacities of the warmer and cooler liquid, $V$ and $V_{c}\left(\mathrm{~m}^{3}\right)$ are the volumes of the warmer and cooler liquid in the heat exchanger, $\rho$ and $\rho_{c}\left(\mathrm{~kg} . \mathrm{m}^{3}\right)$ are the densities of the warmer and cooler liquid and $\alpha\left(\mathrm{kJ} \cdot \mathrm{m}^{-2} \cdot \mathrm{K}^{-1} \cdot \mathrm{s}^{-1}\right)$ is the heat transfer coefficient. 


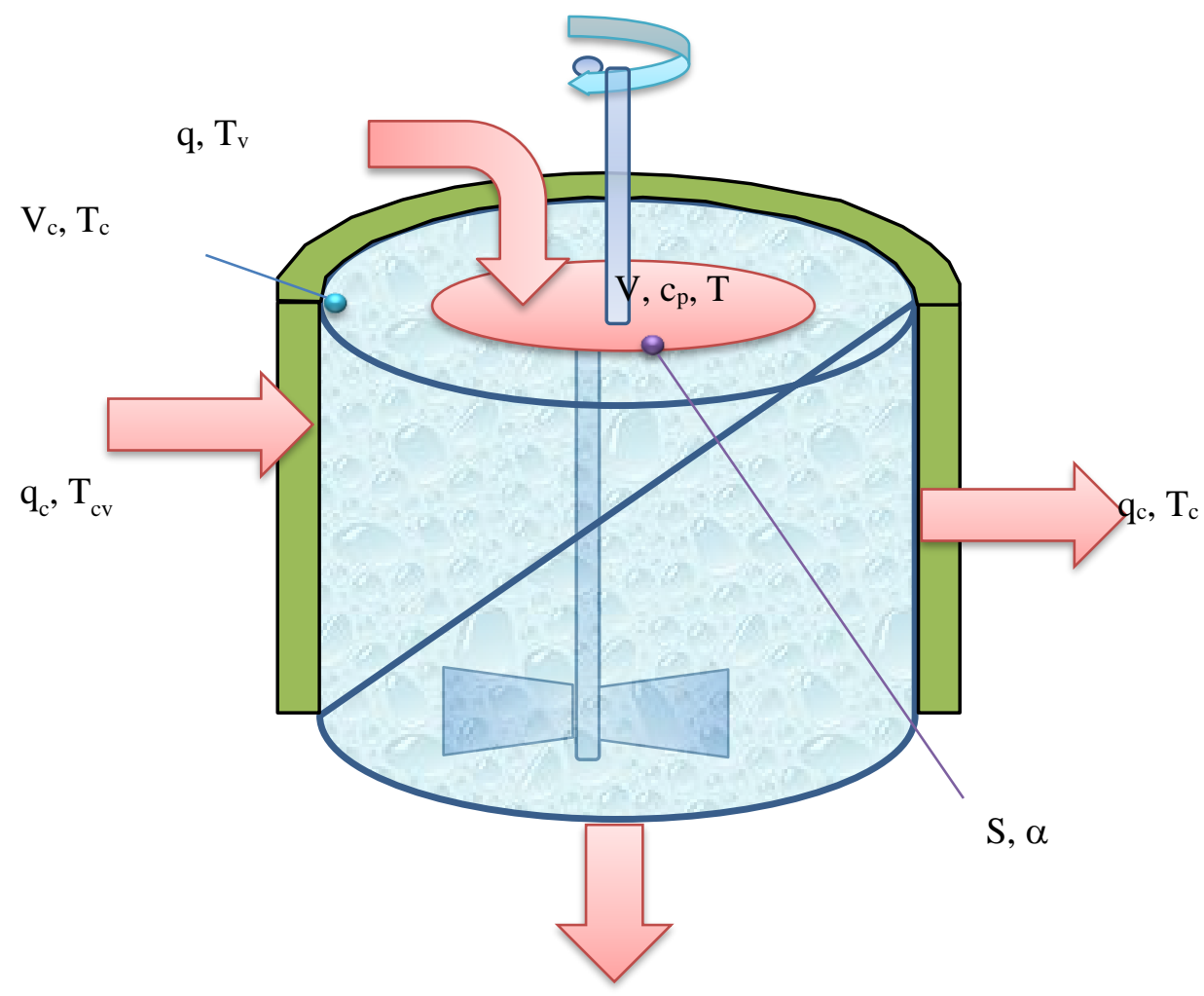

q, T

Fig. 7. Scheme of the cylindrical flow heat exchanger with stirring

It is clear from the equations that it is the system with multiple inputs multiple outputs, namely system with two inputs and two outputs. Now we select the state space variables as $x_{1}=T, x_{2}=T_{c}, u_{1}=q$ and $u_{2}=q_{c}$ and we obtain the nonlinear system as

$$
\begin{aligned}
& \dot{x_{1}}=-\frac{S \alpha}{V \rho c_{p}} x_{1}+\frac{S \alpha}{V \rho c_{p}} x_{2}+\frac{T_{v}-T}{V} u_{1} \\
& \dot{x_{2}}=-\frac{S \alpha}{V_{c} \rho_{c} c_{p c}} x_{1}+\frac{S \alpha}{V_{c} \rho_{c} c_{p c}} x_{2}+\frac{T_{c v}-T_{c}}{V_{c}} u_{1} \\
& \mathbf{f}=\left[\begin{array}{cc}
-\frac{S \alpha}{V \rho c_{p}} & x_{1}+\frac{S \alpha}{V \rho c_{p}} x_{2} \\
\frac{S \alpha}{V_{c} \rho_{c} c_{p c}} x_{1}-\frac{S \alpha}{V_{c} \rho_{c} c_{p c}} x_{2}
\end{array}\right] \\
& \mathbf{G}=\left[\begin{array}{cc}
\frac{T_{v}-T}{V} & 0 \\
0 & \frac{T_{c v}-T_{c}}{V_{c}}
\end{array}\right]
\end{aligned}
$$

Next picture displays the scheme of this model created in MATLAB-SIMULINK software. 


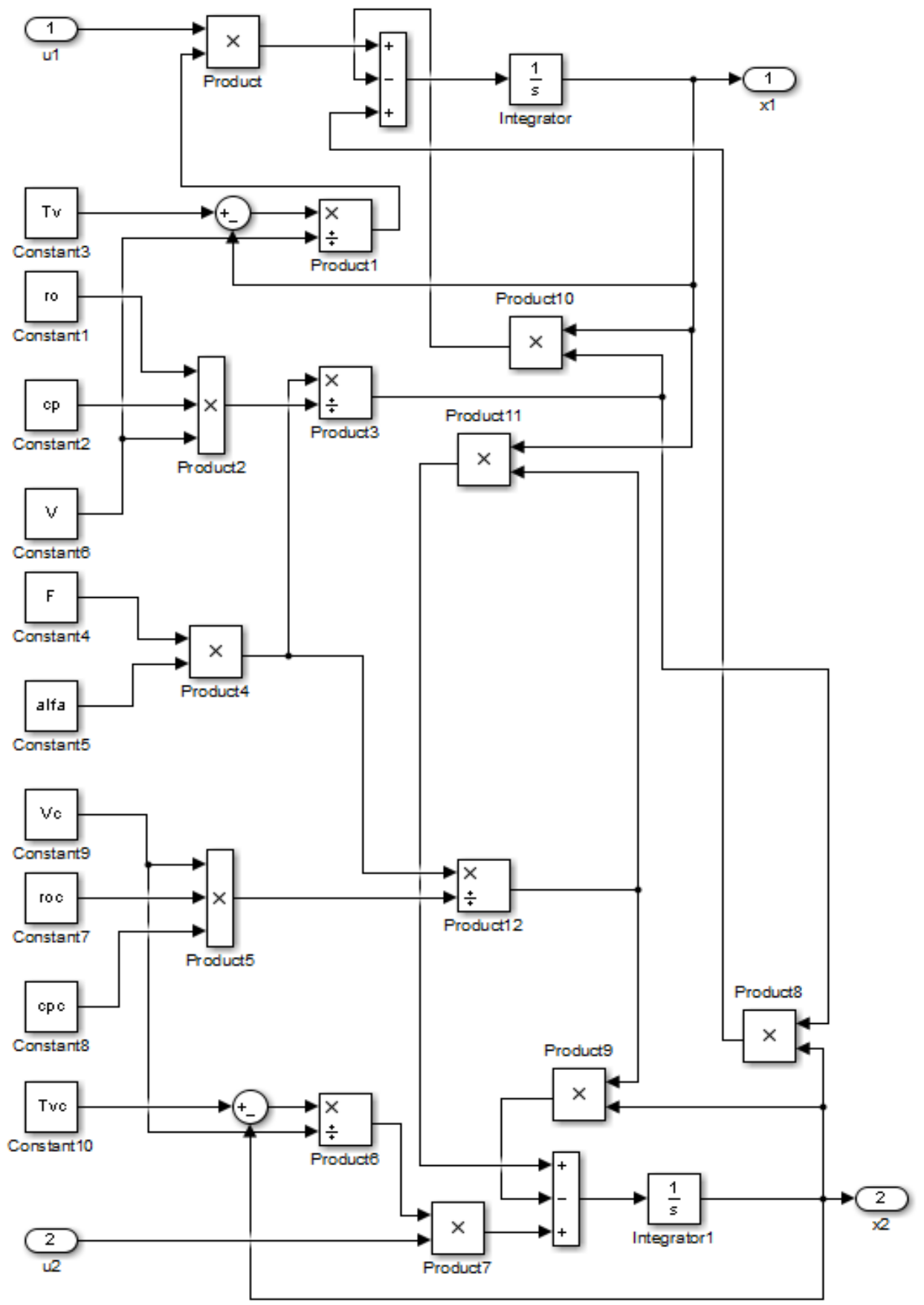

Fig. 8. Model of the cylindrical flow heat exchanger with stirring in MATLAB-SIMULINK environment

\section{Description of Created Didactic Tool}

The models described before were used as a "core" of the didactic tool. There was created the GUI in MATLAB that offers to select the nonlinear model and set the parameters and realize the response of the model on the one of the possible input signals for each input. There is also possible to set the parameters of the nonlinear models in GUI. Plus it is also possible to set the range of the parameters and visualize it all in one graph with the color change. That is one part of the tool.

The set of the videos describing the model derivation and its realization in MATLAB-SIMULINK with explanation what each block means in the derived nonlinear model is the other part of the tool. This part is positively evaluated mostly by students of distance curriculum who did not work with MATLAB in practice. 
The other part of didactic tool consists of web pages explaining the basis of nonlinear systems, their modelling and control including for example types of nonlinearities, examples of Hammerstein and Wiener models, and some methods of nonlinear control of nonlinear systems. All materials are in the Czech language only.

\section{Evaluation of Didactic Tool}

The didactic tool was created for undergraduate students of Bachelor curricula. They have subjects about control theory and practice only marginally because their curricula are mostly oriented on programming. The didactic tool was offered to students during last academic year in both semesters, in regular and distance curriculum.

There was created the following questionnaire:

1) How often you have used the didactic tool? (Always/ Often/ Rarely/ Never)

2) What would you like to change? (Enlarge/ Models from other areas/ Version for smartphones)

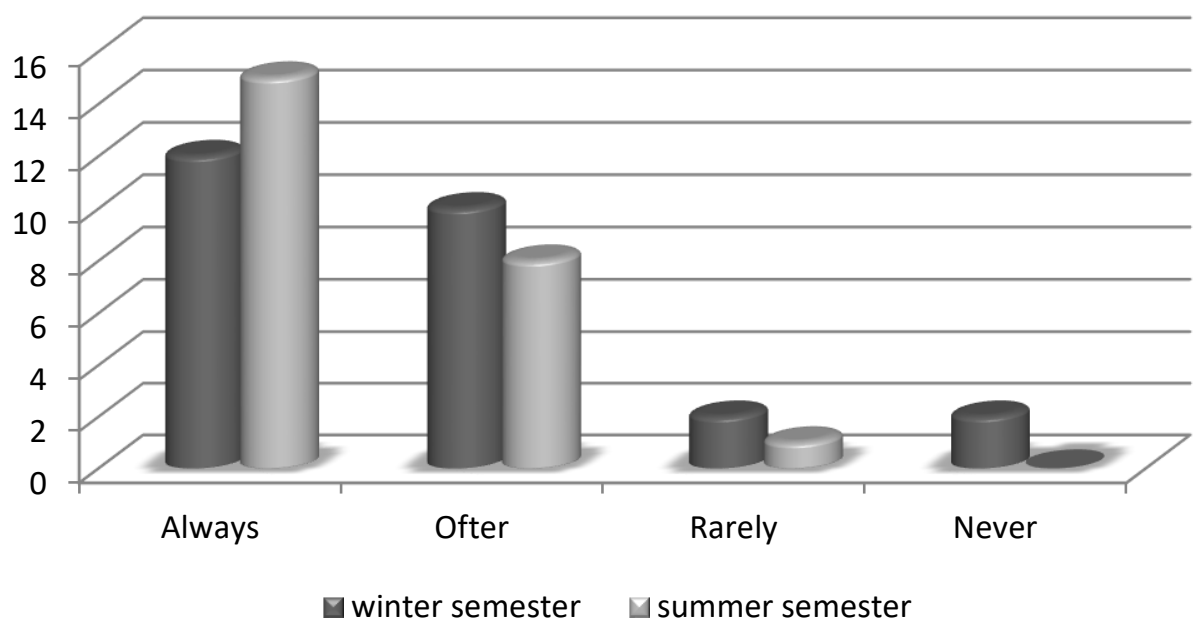

Fig. 9. Evaluation Questionnaire - Question 1 (Regular Curriculum)

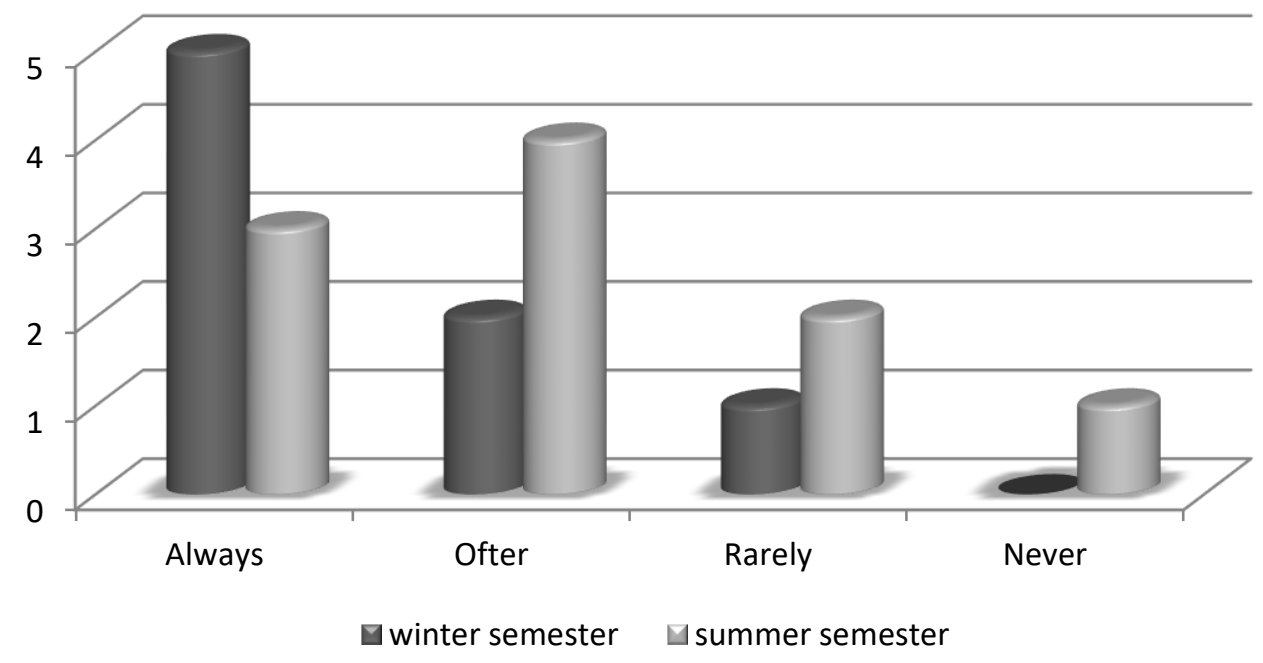

Fig. 10. Evaluation Questionnaire - Question 1 (Distance Curriculum) 


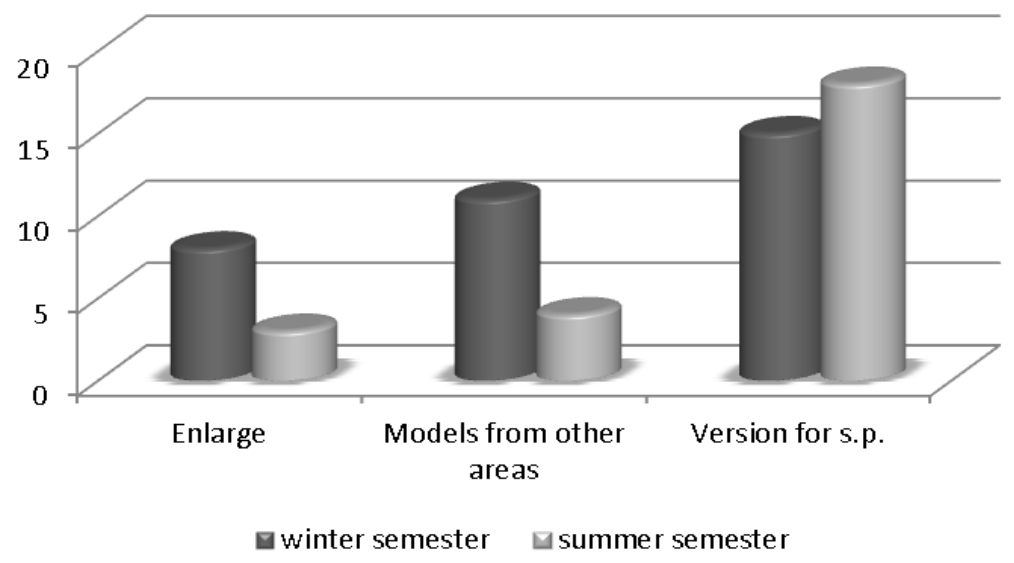

Fig. 11. Evaluation Questionnaire - Question 2 (Regular Curriculum)

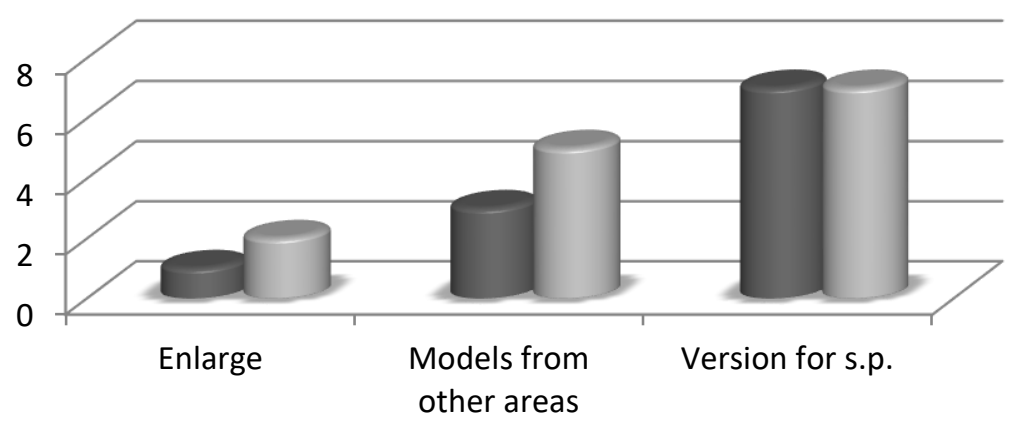

$\square$ winter semester $\square$ summer semester

Fig. 12. Evaluation Questionnaire - Question 2 (Distance Curriculum)

\section{Conclusion}

The paper presented the created didactic tool for students of curricula where also control theory is taught. There were also presented the created and used models and evaluation by students. The main problem was to make the teaching process more attractive. This problem was solved by modern way and the solution was inspired by the experience of the author from the teaching the other subjects using electronic didactic tools, the created new didactic tool is the main result of this work.

Students mostly positively evaluated the created tool and wanted also the new version for smartphones. Therefore, future work will be focused on new version for smartphones. However, it will be only the smaller one than the one for PC. Other enlargements of the PC version will include the programs in MATLAB-SIMULINK realizing the control of nonlinear systems, videos describing the approach of controller design plus describing the realization of control in MATLAB-SIMULINK.

\section{References}

[1] A. M. Fombu, G. Kenné, J. D. Nguimfack-Ndongmo, R. Kuate-Fochie, "Decentralized nonlinear coordinated excitation and steam valve adaptive control for multi-machine power systems," Electrical Power and Energy Systems, vol. 75, pp. 117-126, 2016.

[2] S. Rasoulian, L. A. Ricardez-Sandoval, "Stochastic nonlinear model predictive control applied to a thin film deposition process under uncertainty," Chemical Engineering Science, vol. 40, pp. 90-13, 2016.

[3] H. Omran, L. Hetel, M. Petreczky, J.-P. Richard, F. Lamnabhi-Lagarrigue, "Stability analysis of some classes of input-affine nonlinear systems with aperiodic sampled-data control,” Automatica, vol. 70, pp. 266-274, 2016.

[4] H. L. Dai, A. Abdelkefi, L. Wang., "Usefulness of passive non-linear energy sinks in controlling galloping vibrations," International Journal of Non-Linear Mechanics, vol. 81, pp. 83-94, 2016.

[5] O. I. Tacha, Ch. K. Volos, I. M. Kyprianidis, I. N. Stouboulos, S. Vaidyanathan, V.-T. Pham, “Analysis, adaptive control and circuit simulation of a novel nonlinear finance system," Applied Mathematics and Computation, vol. 276, pp. 200-217, 2016. 
[6] P. Chen, J. Wang, "Estimation and adaptive nonlinear model predictive control of selective catalytic reduction systems in automotive applications," Journal of Process Control, vol. 40, pp. 78-92, 2016.

[7] J. Zhang, H. Liang, T. Feng, "Optimal control of nonlinear continuous systems by adaptive dynamic programming based on fuzzy basis functions," Applied Mathematical Modelling, article in press.

[8] L. Rodríguez-Guerrero, O. Santos-Sánchez, S. Mondié, “A constructive approach for an optimal control applied to a class of nonlinear time delay systems," Journal of Process Control, vol. 40, pp. 35-49, 2016.

[9] C. Zhang, H. Li, "A generalized robust decentralized control methodology for a class of interconnected nonlinear systems subject to uncertainties and disturbances," Nonlinear Analysis: Hybrid Systems, vol. 22, pp. 55-71, 2016.

[10] S. Gao, B. Ning, H. Dong, "Fuzzy dynamic surface control for uncertain nonlinear systems under input saturation via truncated adaptation approach," Fuzzy Sets and Systems, vol. 290, pp. 100-117, 2016.

[11] J. Mao. Z. Xiang, S. Huang, "Adaptive finite-time tracking control for a class of switched nonlinear systems with unmodeled dynamics," Neurocomputing, vol. 196, pp. 42-52, 2016.

[12] P. Jiang, "Multiple-targets tracking algorithm for a class of nonlinear systems with feedforward compensations," Neurocomputing, vol. 196, pp. 210-213, 2016.

[13] D. K. Rollins, Y. Mei, S. D. Loveland, N. Bhandari, "Block-oriented feedforward control," Chemical Engineering Research and Design, vol. 109, pp. 397-404, 2016.

[14] Y. Ren, L. Li, J. Bridley, L. Jiang, "Nonlinear PI control for variable pitch wind turbine," Control Engineering Practice, vol. 50, pp. 84-94, 2016.

[15] L.-B. Wu, G.-H. Yang, "Adaptive fuzzy tracking control for a class of uncertain nonaffine nonlinear systems with dead-zone inputs," Fuzzy Sets and Systems, vol. 290, pp. 1-21, 2016.

[16] H. Li, Y. Shi, W. Yan, "Distributed receding horizon control of constrained nonlinear vehicle formations with guaranteed $\gamma$-gain stability," Automatica, vol. 68, pp. 148-154, 2016.

[17] B. G. B. Hunnekens, N. v. d. Wouw, D. Nešić, "Overcomming a fundamental time-domain performance limitation by nonlinear control," Automatica, vol. 67, pp. 277-281, 2016.

[18] J. Wilson, M. Charest, R. Dubay, "Non-linear model predictive control schemes with application on 2 link vertical robot manipulator," Robotics and Computer-Integrated Manufacturing, vol. 41, pp. 23-30, 2016.

[19] D. J. Pradeep, M. M. Noel, N. Arun, "Nonlinear control of a boost converter using a robust regression based reinforcement learning algorithm,” Engineering Applications of Artificial Intelligence, vol. 52, pp. 1-9, 2016.

[20] K.-K. K. Kim, E. Ríos-Patrón, R. D. Braatz, "Robust nonlinear internal model control of stable Wiener systems," Journal of Process Control, vl. 22, pp. 1468-1477, 2012.

[21] P. Dreesen, M. Ishteva, J. Schoukens, "Recovering Wiener-Hammerstein nonlinear state-space models using linear algebra," IFAC-PapersOnLine, vol. 48, pp. 951-956, 2015.

[22] F. Ding, X. Liu, M. Liu, "The recursive least squares identification algorithm for a class of Wiener nonlinear systems," Journal of Franklin Institute, vol. 353, pp. 1518-1526, 2016.

[23] S. Li, Y. Li, "Model predictive control of an intensified continuous reactor using a neural network model," Neurocomputing, vol. 185, pp. 93-104, 2016.

[24] Y. Zhao, Y. Jiang, J. Feng, L. Wu, "Modeling of memristor-based chaotic systems using nonlinear Wiener adaptive filters based on backlash operator," Chaos, Solitons and Fractals, vol. 87, pp. 12-16, 2016.

[25] D. K. Rollins, Y. Mei, S. D. Loveland, N. Bhandari, "Block-oriented feedforward control with demonstration to nonlinear parametrized Wiener modeling," Chemical Engineering Research and Design, vol. 109, pp. 397-404, 2016.

[26] H. Salhi, S. Kamoun, "A recursive parametric estimation algorithm of multivariable systems described by Hammerstein mathematical models," Applied Mathematical Modelling, vol. 39, pp. 4951-4962, 2015.

[27] M. Lawryńczuk, "Nonlinear predictive control for Hammerstein-Wiener systems," ISA Transactions, vol. 55, pp. 49-62, 2015.

[28] M. Bubenikova, "Control of SISO systems with given type of nonlinearity", thesis, Tomas Bata University in Zlin, 89 p., 2007.

[29] F. Khani, M. Haeri, "Robust model predictive control of nonlinear processes represented by Wiener or Hammerstein models," Chemical Engineering Science, vol. 129, pp. 223-231, 2015.

[30] Z. Zhou, D. Zhao, X. Liu, Y. Guo, Ch. Guan, W. Feng, N. Guo, "Pole-placement self-tuning control of nonlinear Hammerstein system and its application to $\mathrm{pH}$ process control," Chinese Journal of Chemical Engineering, vol. 23, pp. 1346-1368, 2016.

[31] Q. Zhang, Q. Wang, G. Li, "Nonlinear modeling and predictive functional control of Hammerstein system with application to the turnable servo system," Mechanical Systems and Signal Processing, vol. 72-73, pp. 383-394, 2016.

[32] N. Wang, J.-Ch. Sun, Y.-Ch. Liu, "Direct adaptive self-structuring fuzzy control with interpretable fuzzy rules for a class of nonlinear uncertain systems," Neurocomputing, vol. 173, pp. 1640-1645, 2016.

[33] V.E. Pryanichnikov, B. Katalinic, A.A. Kirilchenko, R.V. Khelemendik, S.V. Kuvshinov, D. Vician, A. Uglesic, "New Creative Educational Technologies for Inter-university Network," Procedia Engineering, vol. 100, pp. 259$268,2015$. 